\title{
A cluster of lung injury cases associated with home humidifier use: an epidemiological investigation
}

\author{
Hwa Jung Kim, ${ }^{1}$ Moo-Song Lee, ${ }^{1,2}$ Sang-Bum Hong, ${ }^{3}$ Jin Won Huh, ${ }^{3}$ \\ Kyung-Hyun Do, ${ }^{4}$ Se Jin Jang, ${ }^{5}$ Chae-Man Lim, ${ }^{3}$ Eun Jin Chae, ${ }^{4}$ Hanyi Lee, $^{6}$ \\ Miran Jung, ${ }^{7}$ Young-Joon Park, ${ }^{8}$ Ji-Hyuk Park, ${ }^{9}$ Geun-Yong Kwon, ${ }^{9}$ Jin Gwack, ${ }^{9}$ \\ Seung-Ki Youn, ${ }^{9}$ Jun-Wook Kwon, ${ }^{10}$ Byung-Guk Yang, ${ }^{11}$ Byung-Yool Jun, ${ }^{12}$ \\ Yangho Kim, ${ }^{13}$ Hae-Kwan Cheong, ${ }^{14}$ Byung Chul Chun, ${ }^{15}$ Heon Kim, $^{16}$ \\ Kyuhong Lee, ${ }^{17}$ Younsuck Koh ${ }^{3}$
}

- Additional material is published online only. To view please visit the journal online (http://dx.doi.org/10.1136/ thoraxjn-2013-204132)

For numbered affiliations see end of article.

\section{Correspondence to} Moo-Song Lee, Department of Clinical Epidemiology and Biostatistics, Department of Preventive Medicine, Asan Medical Center, University of Ulsan College of Medicine 43-gil Olympic-ro, Songpa-gu, Seoul 138-736, Korea; lee.moosong.md@gmail.com, leems@amc.seoul.kr

Received 9 July 2013 Revised 3 January 2014 Accepted 9 January 2014 Published Online First 31 January 2014

\section{SLinked}

- http://dx.doi.org/10.1136/ thoraxjnl-2013-204135

- http://dx.doi.org/10.1136/ thoraxjnl-2014-205739

\section{CrossMark}

To cite: Kim HJ, Lee M-S, Hong S-B, et al. Thorax 2014;69:703-708.

\section{ABSTRACT}

Background In April 2011 a tertiary hospital in Seoul, Korea reported several cases of severe respiratory distress of unknown origin in young adults.

Methods To find the route of transmission, causative agent and patient risk factors of the outbreak, an investigation of the epidemic was initiated.

Clinicopathological conferences led to the suspicion that the cases related to an inhalation injury. An age- and sex-matched case-control study was therefore performed to examine the inhalation exposure of the patients to various agents.

Results Of the 28 confirmed cases, 18 agreed to participate. A total of 121 age- and sex-matched controls with pulmonary, allergic or obstetric disease were selected. All patients and controls completed questionnaires with questions about exposure to various inhalants. The crude ORs for patient exposure to indoor mould, humidifier use, humidifier detergent use and insecticide use were $4.4(95 \% \mathrm{Cl} 1.5$ to 13.1$), 13.7$ (95\% Cl 1.8 to 106.3$), 47.3$ (95\% Cl 6.1 to 369.7 ) and $3.9(95 \% \mathrm{Cl} 1.3$ to 11.7$)$, respectively. However, when considered concurrently, indoor mould and insecticide use lost statistical significance. Moreover, humidifier use was ruled out as the cause because of a lack of biological plausibility and the weak strength of the association. This suggested that humidifier disinfectant was the cause of the outbreak. This information led the Korean government to order the removal of humidifier detergents from the market. In the years following the ban, no additional cases were detected.

Conclusions Epidemiological evidence strongly suggests that the lung injury outbreak was caused by humidifier detergent use at home.

\section{INTRODUCTION}

Numerous chemicals are being used today and many have been proved to promote the development of lung diseases. However, the vast majority of chemicals have not been tested for toxicity in humans. Most chemical inhalation injuries are reported after occupational or accidental exposures. ${ }^{1}{ }^{2}$ However, household chemicals are often used frequently or continuously; over time, this can result in considerable cumulative exposure, even

\section{Key messages}

What is the key question?

- What was the main cause of the respiratory disease observed in the cluster of mostly peripartum women who were admitted to the ICU in the spring of 2011 in Korea?

What is the bottom line?

- Continuous inhalation of household chemicals such as humidifier detergent can cause severe respiratory distress in previously healthy adults, especially among a susceptible population such as peripartum women.

Why read on?

- This tragedy led us to realise that household chemical inhalation can cause severe respiratory distress, so stronger safety regulations that protect the public from toxic inhalants at home are warranted.

though only a small amount is used at each time. This threat to safety by household chemicals generally remains poorly understood.

Between 1 April and 6 May 2011 the intensive care unit of a tertiary university hospital in Seoul received eight cases of severe respiratory distress of unknown origin and reported them to the Centers for Disease Control and Prevention (KCDC). The cases were all young adults who were previously healthy and had no specifically known risk factors in common. ${ }^{3}$ The patients were also located all over the nation. The clinical presentation of all the cases suggested a diagnosis of acute interstitial pneumonia or hypersensitivity pneumonitis, but the radiological and pathological findings were not consistent with this. ${ }^{4} 5$ This raised the possibility that the cases represented an epidemic of a new disease.

After several conferences with the clinical team and the KCDC, a case-control study was conducted to identify the route of transmission, causative agent and the patient risk factors that promoted their susceptibility to this disease. 


\section{METHODS}

On 12 May 2011, in cooperation with the KCDC, a professional epidemiological investigation team consisting of epidemiologists, pulmonologists, radiologists, pathologists, infection specialists and obstetricians was established to investigate the epidemiological, clinical and microbiological characteristics of the outbreak. After several multidisciplinary conferences, the disease was suspected to be an inhalation injury with a subacute nature that was caused by exposure to an indoor agent (details of the process that led to this hypothesis are described in the accompanying article).

\section{Case definition and case findings}

At the time the outbreak was identified there were 12 suspected cases. The conferences led to a working definition of the disease: to diagnose the disease, the following three characteristics had to be present: (1) bilateral, centrilobular or diffuse ground glass opacities observed on high-resolution CT (HRCT); (2) the patients had symptoms or signs not consistent with other clinical diagnoses; and (3) the patients were young adults aged 20-54 years.

Thereafter, all HRCT images taken between 1 January 2006 and 30 September 2011 in patients aged 20-54 years were reviewed. Patients with cancer, chronic obstructive pulmonary disease or a definite diagnosis of another disease were excluded from further review. To minimise misclassification of the cases, other information such as that in medical records or physical examinations was also used. All suspected cases were requested for further evaluation by a pulmonologist for confirmation.

\section{Control selection and data collection}

The control subjects were selected from patients who visited the departments of pulmonology (PLM), allergy (ALG) and obstetrics/gynaecology (OBGY) in the same tertiary university hospital between 1 June and 15 July 2011. Each case was matched with four controls according to age ( \pm 5 years) and sex as matching variables. For each female case, there were one, one and two PLM, ALG and OBGY controls, respectively. For each male case there were two, two and no PLM, ALG and OBGY controls, respectively.

\section{Data collection}

All confirmed patients were contacted personally and interviewed so that a constructed questionnaire that focused on inhalation exposures, especially to indoor agents, could be completed. The questionnaire also had questions about clinical history, details of any previous respiratory symptoms or lung diseases, demographic factors, past medical history, family history, social history, personal hygiene, medication use and others. Standard operating procedures were adopted in the interviews and physical examinations to standardise the data collection process. To determine the exposure status prior to the index date, the questionnaire was specially designed to help the patients recall their memories. We conducted the same interview process on controls, and the same information collection procedure was conducted for each case.

\section{Data management and statistical analysis}

The completed questionnaire and medical record data were entered into a computerised database using the double data entry method. All missing values and outliers were checked manually against the original data. After this validation process, the database was locked.

The cases and controls were compared in terms of their baseline characteristics by $\chi^{2}$ test or Student $t$ test, as required. A logistic regression model was then used to calculate the risk of severe respiratory distress that was associated with the inhalation of each potential risk factor. The potential risk factors were deemed to be those whose $\mathrm{p}$ value was $<0.2$ in univariate analysis. All were included in the multivariable analysis if they were clinically plausible and if they remained statistically significant on subgroup analysis. All tests were two-sided. A p value of 0.05 was considered to indicate statistical significance. Statistical analysis was conducted using the SAS System for Windows release V.9.2 (SAS Institute, Cary, North Carolina, USA).

\section{RESULTS}

\section{Characteristics of cases and controls}

All HRCT images taken between 2001 and 2011 were reviewed by using keywords such as centrilobular or diffuse ground glass opacities, acute interstitial pneumonia, hypersensitivity pneumonitis, etc. About 1500 images were selected. Analysis of these images showed that 34 patients were suspected to have had the disease. Of these, 28 were confirmed cases (figure 1) and 18 agreed to participate in the case-control study. A total of 121 control patients were selected (55, 30 and 36 PLM, ALG and OBGY patients, respectively).

The cases consisted of three men and 15 women; their mean ages were 44.0 and 35.3 years, respectively. Due to the matched study design, the cases did not differ significantly from the three
Figure 1 Number of identified cases with home humidifier-associated lung injury.

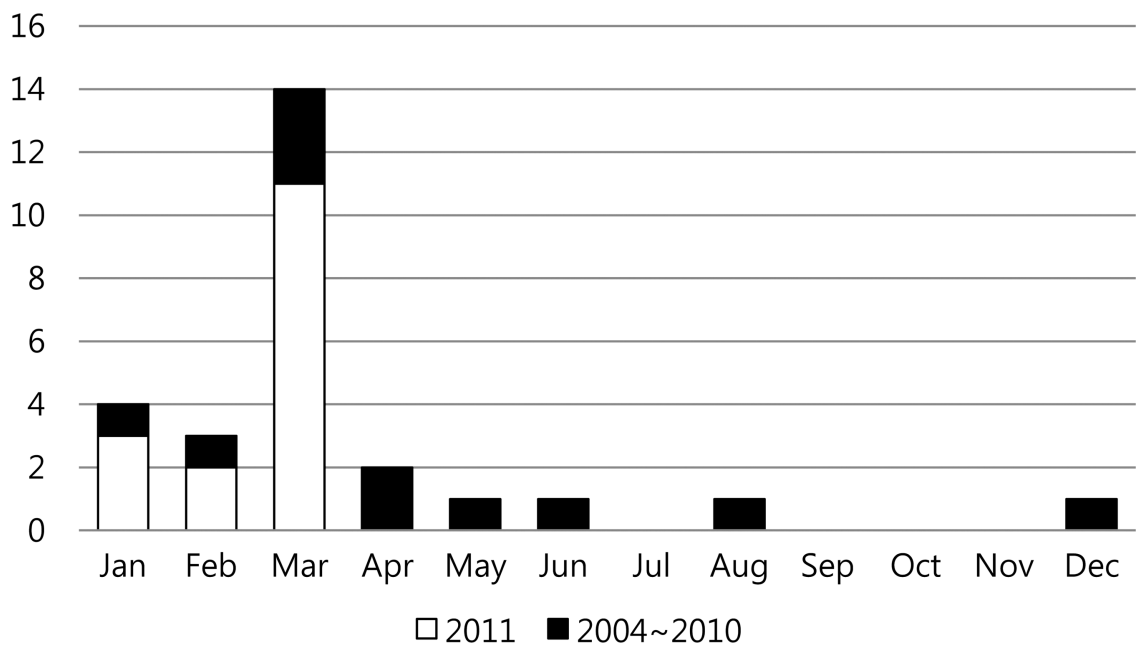


control groups in terms of age or gender distribution $(p=0.86$ and $\mathrm{p}=0.72$ ). While the cases did not differ significantly from the controls in terms of marital status $(p=0.40)$, they were significantly more likely to have one or more children than the controls $(p=0.01)$. The two groups did not differ in terms of other sociodemographic and clinical characteristics (table 1).

\section{Indoor and outdoor exposure of cases and controls}

The questionnaire was used to assess the degree of exposure to various indoor and outdoor environmental factors. With regard to the indoor factors, the cases were significantly more likely to have been exposed to indoor mould, humidifiers, humidifier detergent and insecticide than the controls $(p<0.01, p<0.01$, $\mathrm{p}<0.01$ and $\mathrm{p}=0.03$, respectively). In fact, 17 of the 18 cases (94.4\%) used a humidifier before the index date compared with only 67 of the 121 controls $(55.4 \% ; \mathrm{p}<0.01)$. Moreover, all 17 cases who used humidifiers also used humidifier detergents (94.4\%) while only 32 controls (26.4\%) reported using humidifier detergents $(\mathrm{p}<0.01)$. By contrast, the controls were more likely than the cases to have undertaken house renovations, bought new furniture, used an air cleanser and been exposed to dust and pollen $(\mathrm{p}=0.02, \mathrm{p}<0.01, \mathrm{p}<0.01$ and $\mathrm{p}=0.04$, respectively) (table 2 ).

Table 1 Sociodemographic and clinical characteristics of study participants in the case-control study

\begin{tabular}{|c|c|c|c|}
\hline & Cases $(n=18)$ & Controls $(n=121)$ & p Value* \\
\hline Cause for visit & & & $<0.01$ \\
\hline Pulmonology & $18(100 \%)$ & $55(45.5 \%)$ & \\
\hline Allergy & $0(0 \%)$ & $30(24.8 \%)$ & \\
\hline Obstetric gynaecology & $0(0 \%)$ & $36(29.8 \%)$ & \\
\hline Age & & & 0.62 \\
\hline $20 \mathrm{~s}$ & $1(5.6 \%)$ & $17(14.0 \%)$ & \\
\hline $30 \mathrm{~s}$ & $13(72.2 \%)$ & $65(53.7 \%)$ & \\
\hline $40 \mathrm{~s}$ & $4(22.2 \%)$ & $35(28.9 \%)$ & \\
\hline $50 \mathrm{~s}$ & $0(0 \%)$ & $4(3.3 \%)$ & \\
\hline Mean \pm SD & $36.8 \pm 5.1$ & $36.5 \pm 6.8$ & 0.86 \\
\hline Sex & & & 0.72 \\
\hline Women & $15(83.3 \%)$ & $104(86.0 \%)$ & \\
\hline Men & $3(16.7 \%)$ & $17(14.0 \%)$ & \\
\hline Marital status & & & 0.40 \\
\hline Not married & $1(5.6 \%)$ & $22(18.2 \%)$ & \\
\hline Married & $17(94.4 \%)$ & $98(81.0 \%)$ & \\
\hline Unknown & $0(0 \%)$ & $1(0.8 \%)$ & \\
\hline Children & & & 0.01 \\
\hline None & $2(11.1 \%)$ & $34(28.1 \%)$ & \\
\hline One or more & $16(88.9 \%)$ & $64(52.9 \%)$ & \\
\hline Unknown & $0(0 \%)$ & $23(19.0 \%)$ & \\
\hline Smoking status & & & 0.06 \\
\hline Non-smoker & $14(77.8 \%)$ & $104(86.0 \%)$ & \\
\hline Ex-smoker & $4(22.2 \%)$ & $8(6.6 \%)$ & \\
\hline Current smoker & $0(0 \%)$ & $9(7.4 \%)$ & \\
\hline \multicolumn{4}{|l|}{ Past medical history } \\
\hline Atopic dermatitis & $0(0 \%)$ & $3(2.5 \%)$ & 1.00 \\
\hline Asthma & $2(11.1 \%)$ & $14(11.6 \%)$ & 1.00 \\
\hline Allergy & $3(16.7 \%)$ & $16(13.2 \%)$ & 0.71 \\
\hline Respiratory disease & $0(0 \%)$ & $20(16.5 \%)$ & 0.07 \\
\hline Others & $2(11.1 \%)$ & $20(16.5 \%)$ & 0.74 \\
\hline
\end{tabular}

${ }^{*} p$ Values were calculated by using the $\chi^{2}$ test or Student $t$ test depending on the nature of the variable.
Table 2 Comparison of cases and controls in terms of indoorl outdoor environmental factors

\begin{tabular}{|c|c|c|c|}
\hline & $\begin{array}{l}\text { Cases } \\
(n=18)\end{array}$ & $\begin{array}{l}\text { Controls } \\
(n=121)\end{array}$ & $\begin{array}{l}p \\
\text { Value }\end{array}$ \\
\hline House renovation in the previous year & & & 0.02 \\
\hline No & $18(100 \%)$ & $84(69.4 \%)$ & \\
\hline Yes & $0(0 \%)$ & $34(28.1 \%)$ & \\
\hline Unknown & $0(0 \%)$ & $3(2.5 \%)$ & \\
\hline New furniture in the previous year & & & $<0.01$ \\
\hline No & $15(83.3 \%)$ & $46(38.0 \%)$ & \\
\hline Yes & $3(16.7 \%)$ & $74(61.2 \%)$ & \\
\hline Unknown & $0(0 \%)$ & $1(0.8 \%)$ & \\
\hline New wall in the previous year & & & $<0.01$ \\
\hline No & $16(88.9 \%)$ & $49(40.5 \%)$ & \\
\hline Yes & $2(11.1 \%)$ & $72(59.5 \%)$ & \\
\hline Indoor mould in the previous year & & & 0.01 \\
\hline No & $5(27.8 \%)$ & $76(62.8 \%)$ & \\
\hline Yes & $13(72.2 \%)$ & $45(37.2 \%)$ & \\
\hline Carpet in the house & & & 0.24 \\
\hline No & $17(94.4 \%)$ & $93(76.9 \%)$ & \\
\hline Yes & $1(5.6 \%)$ & $27(22.3 \%)$ & \\
\hline Unknown & $0(0 \%)$ & $1(0.8 \%)$ & \\
\hline Air cleanser & & & 0.04 \\
\hline No & $14(77.8 \%)$ & $78(64.5 \%)$ & \\
\hline Yes & $4(22.2 \%)$ & $17(14.0 \%)$ & \\
\hline Unknown & $0(0 \%)$ & $26(21.5 \%)$ & \\
\hline Air conditioner & & & 0.09 \\
\hline No & $8(44.4 \%)$ & $30(24.8 \%)$ & \\
\hline Yes & $10(55.6 \%)$ & $91(75.2 \%)$ & \\
\hline Humidifier & & & $<0.01$ \\
\hline No & $1(5.6 \%)$ & $54(44.6 \%)$ & \\
\hline Yes & $17(94.4 \%)$ & $67(55.4 \%)$ & \\
\hline Humidifier detergent & & & $<0.01$ \\
\hline No & $1(5.6 \%)$ & $89(73.6 \%)$ & \\
\hline Yes & $17(94.4 \%)$ & $32(26.4 \%)$ & \\
\hline Insecticide & & & 0.03 \\
\hline No & $5(27.8 \%)$ & $72(59.5 \%)$ & \\
\hline Yes & $13(72.2 \%)$ & $48(39.7 \%)$ & \\
\hline Unknown & $0(0 \%)$ & $1(0.8 \%)$ & \\
\hline Dust & & & $<0.01$ \\
\hline No & $17(94.4 \%)$ & $49(40.5 \%)$ & \\
\hline Yes & $1(5.6 \%)$ & $71(58.7 \%)$ & \\
\hline Unknown & $0(0 \%)$ & $1(0.8 \%)$ & \\
\hline Pollen & & & 0.04 \\
\hline No & $16(88.9 \%)$ & $71(58.7 \%)$ & \\
\hline Yes & $2(11.1 \%)$ & $48(39.7 \%)$ & \\
\hline Unknown & $0(0 \%)$ & $2(1.7 \%)$ & \\
\hline
\end{tabular}

The cases and controls did not differ in terms of exposure to outdoor environmental factors including living in residential neighbourhoods and having outside facilities within $2 \mathrm{~km}$ (table 2 and online supplementary e-Table 1).

Indoor mould, humidifier use, humidifier detergent use and insecticide use were included in the logistic regression model. However, only the previous use of humidifier detergents remained consistently significant when comparisons with each of the control subgroups were made; the crude and confounderadjusted ORs for this variable relative to the entire control cohort were 47.3 (95\% CI 6.05 to 369.7 ) and 53.0 (95\% CI 
Table 3 Strength of the association between the lung injury and indoor environmental factors

\begin{tabular}{|c|c|c|c|c|c|c|}
\hline & COR & $(95 \% \mathrm{Cl})$ & $\mathrm{aOR}^{*}$ & $(95 \% \mathrm{Cl})$ & aORt & $(95 \% \mathrm{Cl})$ \\
\hline \multicolumn{7}{|c|}{ Compared with all controls $(n=121)$} \\
\hline Indoor moulds & 4.39 & (1.47 to 13.13 ) & 4.19 & (1.30 to 13.53$)$ & 5.03 & (1.35 to 18.80$)$ \\
\hline Humidifier & 13.70 & (1.77 to 106.26$)$ & 14.44 & (1.77 to 117.91$)$ & - & \\
\hline Humidifier detergent & 47.27 & (6.05 to 369.69 ) & - & & 53.01 & (6.33 to 444.17 ) \\
\hline Insecticide & 3.90 & (1.31 to 11.65$)$ & 3.86 & (1.13 to 13.20$)$ & 4.00 & (0.97 to 16.51$)$ \\
\hline \multicolumn{7}{|c|}{ Compared with controls with pulmonary disease $(n=55)$} \\
\hline Indoor moulds & 3.90 & (1.22 to 12.49$)$ & 6.68 & (1.52 to 29.38$)$ & 6.23 & (0.94 to 41.41$)$ \\
\hline Humidifier & 15.24 & (1.89 to 122.62$)$ & 22.87 & (2.34 to 223.26 ) & - & \\
\hline Humidifier detergent & 54.92 & (6.66 to 453.23$)$ & - & & 116.82 & (9.88 to $\infty)$ \\
\hline Insecticide & 3.02 & (0.94 to 9.64$)$ & 7.31 & (1.46 to 36.55$)$ & 15.93 & (1.94 to 130.84$)$ \\
\hline \multicolumn{7}{|c|}{ Compared with controls with allergic disease $(n=30)$} \\
\hline Indoor moulds & 3.90 & $(1.10$ to 13.80$)$ & 3.92 & (0.82 to 18.63$)$ & 3.98 & (0.63 to 25.05$)$ \\
\hline Humidifier & 11.33 & $(1.33$ to 96.80$)$ & 21.14 & (1.70 to 263.40$)$ & - & \\
\hline Humidifier detergent & 34.00 & (3.94 to 293.32 ) & - & & 72.87 & $(4.34$ to $\infty)$ \\
\hline Insecticide & 5.20 & (1.45 to 18.71$)$ & 4.73 & (0.99 to 22.62$)$ & 5.55 & (0.83 to 37.05$)$ \\
\hline \multicolumn{7}{|c|}{ Compared with controls with obstetric disease $(n=36)$} \\
\hline Indoor moulds & 9.09 & (2.13 to 38.77$)$ & 8.59 & (1.50 to 49.19$)$ & 15.03 & (1.66 to 136.45$)$ \\
\hline Humidifier & 11.20 & (1.33 to 94.47$)$ & 10.01 & (0.68 to 147.80$)$ & - & \\
\hline Humidifier detergent & 42.00 & (4.82 to 365.82$)$ & - & & 71.32 & (3.71 to $\infty)$ \\
\hline Insecticide & 4.87 & (1.29 to 18.42$)$ & 2.92 & (0.55 to 15.53$)$ & 1.32 & (0.13 to 13.12$)$ \\
\hline
\end{tabular}

*Adjusted OR from multivariable analysis that included exposure to indoor mould, humidifier use and insecticide use.

tAdjusted OR from multivariable analysis that included exposure to indoor mould, humidifier detergent use and insecticide use.

$\mathrm{aOR}$, adjusted $\mathrm{OR}$; $\mathrm{COR}$, crude $\mathrm{OR}$.

6.33 to 444.17$)$. By contrast, exposure to indoor mould was generally no longer significant when the cases were compared with the PLM and ALG controls, although the comparison of cases versus OBGY controls was significant. Similarly, exposure to humidifier or insecticide was not significant in comparisons with some of the control subgroups (table 3).

It was concluded that humidifier detergent use was the most important risk factor, and 16 of the cases were surveyed again to obtain details about their humidifier and humidifier detergent use (table 4). Another 12 cases that arose between 2004 and 2011 were also surveyed. The majority $(75 \%$ of the 16 cases and $83.3 \%$ of the additional 12 cases) had used detergents containing polyhexamethyleneguanidine (PHMG). In September 2011 an experimental study in an animal model was conducted to test whether humidifier detergent inhalation could induce lung injury. The study found that inhalation of humidifier detergent after its dispersal by humidifiers did indeed induce severe respiratory injury in the animals that was characterised by the same clinical, radiological and histological features as those observed in the human cases. Consequently, the Ministry of Health and Welfare of South Korea issued an order that humidifier detergents should be withdrawn from the market; it also announced the danger of these detergents and advised that humidifier detergents should no longer be used. Thereafter, the KCDC established a surveillance system to detect all further incident cases, and none were observed in the ensuing 2 years.

\section{DISCUSSION}

We report an outbreak of lung injury that was associated with the use of home humidifiers. This is the first case-control study to investigate lung injury associated with home humidifier use. Our univariate analyses showed that exposure to indoor mould, humidifier use, humidifier detergent use and insecticide use was significantly associated with the lung injury; however, only detergent use continued to be a statistically significant factor when the cases were compared with each of the control subgroups. None of the other indoor/outdoor environmental factors that were investigated (including chemical sources) were associated significantly with the lung injury.

Since seven of the eight cases that were initially reported between 1 April and 6 May 2011 were peripartum women, it was initially believed at the beginning of the epidemic investigation that pregnancy was a risk factor for the disease. However, this hypothesis was abandoned when further cases arose because four were men and nine were non-peripartum women. Instead, it is likely that the initial perceived association with pregnancy relates to the fact that the cases were significantly more likely to have children than the controls and that this promoted their massive use of humidifiers and detergents.

The suspected mechanism by which humidifier disinfectant use caused the lung injury is described in the accompanying article. Originally, humidifier detergents were introduced to the

Table 4 Results of an additional survey on the humidifier detergent exposure of cases

\begin{tabular}{lrr}
\hline & $\begin{array}{l}2011 \text { cases } \\
(\mathbf{n}=16)\end{array}$ & $\begin{array}{r}\mathbf{2 0 0 4 - 2 0 1 0} \\
\text { case }(\mathbf{n}=12)\end{array}$ \\
\hline $\begin{array}{l}\text { Chemical type } \\
\text { PGH }\end{array}$ & \\
PHMG & $2(12.5 \%)$ & $0(0.0 \%)$ \\
$\begin{array}{l}\text { Unknown } \\
\text { Exposure duration (months, mean } \pm \text { SD) } \\
\text { Lifetime cumulative }\end{array}$ & $2(12.5 \%)$ & $10(83.3 \%)$ \\
$\begin{array}{l}\text { Between 2011F/W } \\
\text { and 2012S/S }\end{array}$ & $17.5 \pm 14.8$ & $2(16.7 \%)$ \\
\hline
\end{tabular}

F/W, fall and winter; PGH, oligo [2-(2-ethoxy) ethoxyethyl] guanidium chloride; PHMG, polyhexamethyleneguanidine; $S / S$, spring and summer. 
market as cleansing detergents for the water tank of humidifiers. However, in Korea, people then quickly started to dilute these detergents in the water to prevent or suppress the growth of moulds, bacteria or algae in their humidifier water tanks. A recent survey in Korea showed that, between 2006 and 2011, about half of humidifier users used humidifier detergents, especially in winter. ${ }^{6}$

After humidifier disinfectants emerged as the culprit of the severe respiratory failure, most humidifier detergents on the Korean market were analysed to determine their chemical ingredients. Most of the humidifier detergents contained one of three chemicals-namely, oligo [2-(2-ethoxy) ethoxyethyl] guanidium chloride (PGH), PHMG and didecyldimethylammonium chloride (DDAC). ${ }^{7}$ These are broad-spectrum antimicrobial agents that are frequently used in various consumer products such as shampoos, skin antiseptics and sanitisers of water systems and swimming pools due to their reported safety in terms of the oral or skin route. ${ }^{8}$ However, the toxicity of these chemicals when they are inhaled is poorly understood: while the US Environmental Protection Agency (EPA) has reported that DDAC inhalation is toxic, the inhalation toxicities of the other chemicals remain unknown. ${ }^{9}$ The toxicities of these humidifier detergents when humans are exposed to them by other unexpected routes also remain to be determined. The cases who participated in the present case-control study mostly reported using humidifier detergents that contained PHMG. Therefore, it could not be determined whether the three chemicals differed in terms of the respiratory responses that they induce. In any case, the present epidemiological investigation has shown that many people may be exposed to potential indoor household chemical inhalation injury, and that this problem may be greater for in-house dwellers such as infants and peripartum women because they are more susceptible to the injurious effects of these inhalants. Stringent safety regulations that protect the public from toxic inhalants at home are warranted.

As a hospital-based case-control study, our study has inherent limitations: (1) selection bias (eg, the study participants were selected from a single centre that does not represent the general population); (2) misclassification bias (eg, the classification of the cases and controls were based on retrospective medical record-based ascertainment); and (3) incomplete blinding (eg, some participants were informed by hearsay and were not completely blinded to the study purpose). However, due to ethical issues and the low incidence of the disease, it was not possible to conduct a clinical trial. Instead, concerted efforts were made to improve the study: the study was conducted at the most feasible centre with the largest number of patients with lung injury and a questionnaire with various risk factors was used to mask the fact that the real factor of interest was the use of humidifiers or humidifier detergents. Moreover, to reduce the possibility of confounding, controls with PLM or ALG disease and controls who were in hospital for obstetric reasons were used for the comparison; none of these three control groups differed significantly in terms of humidifier detergent use.

In conclusion, the present case-control study shows that the use of home humidifier detergent could lead to a new lung injury. This provides additional evidence that household chemicals may pose an unanticipated hazard to human health. Continuous monitoring of the safety of household chemicals should be conducted.

\section{Author affiliations}

${ }^{1}$ Department of Clinical Epidemiology and Biostatistics, Asan Medical Center, University of Ulsan College of Medicine, Seoul, Korea
${ }^{2}$ Department of Preventive Medicine, Asan Medical Center, University of Ulsan College of Medicine, Seoul, Korea

${ }^{3}$ Department of Pulmonary Medicine and Critical Care Medicine, Asan Medical Center, University of Ulsan College of Medicine, Seoul, South Korea

${ }^{4}$ Department of Radiology, Research Institute of Radiology, Asan Medical Center, University of Ulsan College of Medicine, Seoul, Korea

${ }^{5}$ Department of Pathology, Asan Medical Center, University of Ulsan College of

Medicine, Seoul, Korea

${ }^{6}$ Department of Nursing, Hanyang University, Seoul, Korea

${ }^{7}$ Department of Nursing, Asan Medical Center, Seoul, Korea

${ }^{8}$ Division of Vaccine-preventable Diseases Control and National Immunization

Program, Korea Centers for Disease Control and Prevention, Osong, Korea

${ }^{9}$ Division of Epidemic Intelligence Service, Korea Centers for Disease Control and

Prevention, Osong, Korea

${ }^{10}$ Center for Infectious Disease Control, Korea Centers for Disease Control and

Prevention, Osong, Korea

${ }^{11}$ Bureau of Public Health Policy, Ministry of Health and Welfare, Seoul, Korea

${ }^{12}$ Korea Centers for Disease Control and Prevention, Osong, Korea

${ }^{13}$ Department of Occupational and Environmental Medicine, Ulsan University

Hospital, University of Ulsan College of Medicine, Ulsan, Korea

${ }^{14}$ Department of Social and Preventive Medicine, Sungkyunkwan University School of Medicine, Suwon, Korea

${ }^{15}$ Department of Preventive Medicine, Korea University College of Medicine, Seoul, Korea

${ }^{16}$ Department of Preventive Medicine and Medical Research Institute, College of

Medicine, Chungbuk National University, Cheongju, Korea

${ }^{17}$ Inhalation Toxicology Center, Korea Institute of Toxicology, Jeongeup, Korea

Acknowledgements We thank Sung-Han Kim and Sang-Ho Choi (both from the Division of Infection, Department of Internal Medicine, Asan Medical Center, University of Ulsan College of Medicine) for building the working definition of the epidemic investigation.

Contributors HJK, M-SL and YK contributed to the conception and design of the overall epidemiological investigation. This study was designed in close collaboration with S-BH, JWH, C-ML and YK (the clinical doctors who saw and identified the patients with fatal bronchiolitis with lung fibrosis), and K-HD, SJJ and EJC (the medical experts who guided the definition for diagnosis of the disease). All of these authors reviewed the potential cases and confirmed the cases of the study. HJK and $\mathrm{M}$-SL were involved in the study design and the statistical analysis of the case-control study. HJK, HL, Y-JP, YK, BCC and HK helped to construct the questionnaire. HJK, M-SL, HL, MJ, JWH, Y-JP, JG, J-HP and G-YK interviewed the study participants and collected their clinical data. Y-JP, J-HP, G-YK, JG, S-KY, J-HK, $\mathrm{B}-\mathrm{GY}$ and $\mathrm{B}-\mathrm{YJ}$ interviewed the manufacturers of the humidifier disinfectants. $\mathrm{KL}$ designed and conducted the interventional study in animals. HJK, M-SL, YK, HGJ, C-ML, YK and KL interpreted the case series results, the case-control study results and the animal study results. HJK and S-BH drafted the manuscript and HJK revised the manuscript critically for important intellectual content. M-SL is the guarantor. All authors reviewed the study findings and read and approved the final version before submission.

Funding This work was supported by a grant from the Korean Center for Disease Control (4838-304-260-00). This financial support was provided so that the outbreak could be investigated promptly and the risk factor could be defined as soon as possible. However, the sponsor had no direct role in the study design; in the collection, analysis, or interpretation of the data; in the writing of the report; or in the decision to submit the paper for publication.

\section{Competing interests None.}

Patient consent Obtained.

Ethics approval The study was approved by the Institutional Review Board of Asan Medical Center, Seoul, Korea (2011-0408, 2011-0470) in 2011.

Provenance and peer review Not commissioned; externally peer reviewed.

\section{REFERENCES}

1 Taylor AJN. Respiratory irritants encountered at work. Thorax 1996;51:541-5.

2 Chen TM, Malli H, Maslove DM, et al. Toxic inhalational exposures. J Intensive Care Med 2013:28:323-33.

3 Korea Centers for Disease Control and Prevention. Interim report of epidemiological investigation on lung injury with unknown cause in Korea. Public Health Wkly Rep 2011:820-9

4 Selman M, Morrison LD, Noble PW, et al. Idiopathic interstitial pneumonitis. In: Mason RJ, Broaddus VC, Martin TR, et al., eds. Murray and Nadel's textbook of respiratory medicine. 5th ed. Philadelphia, PA: Saunders Elsevier, 2010:1356-97.

5 Rose CS, Lara AR. Hypersensitivity pneumonitis. In: Mason RJ, Broaddus VC, Martin TR, et al., eds. Murray and Nadel's textbook of respiratory medicine. 5th ed. Philadelphia, PA: Saunders Elsevier, 2010:1587-600. 


\section{Respiratory epidemiology}

6 Jeon BH, Park YJ. Frequency of humidifier and humidifier disinfectant usage in Gyeonggi province. Environ Health Toxicol 2012;27:e2012002.

7 Lee JH, Kim YH, Kwon JH. Fatal misuse of humidifier disinfectants in Korea: importance of screening risk assessment and implications for management of chemicals in consumer products. Environ Sci Technol 2012:46:2498-500.
8 Lucas AD. Environmental fate of polyhexamethylene biguanide. Bull Environ Contam Toxicol 2012;88:322-5.

9 United States Environmental Protection Agency. Reregistration eligibility decision for aliphatic alkyl quaternaries (DDAC). August 2006. http://www.epa.gov/oppsrrd1/ REDs/ddac_red.pdf. 